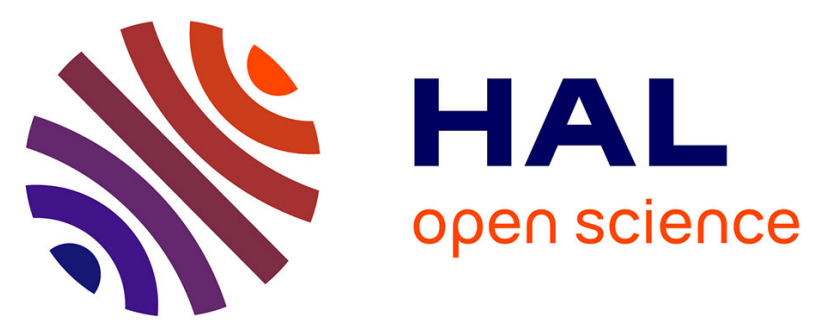

\title{
Analysis of the three-chip switching cells approach for integrated multi-phase power converter combining monolithic and hybrid techniques: Experimental validation on $\mathrm{SiC}$ and $\mathrm{Si}$ power assembly prototypes
}

Adem Lale, Nicolas Videau, Abdelhakim Bourennane, Frédéric Richardeau, Samuel Charlot

\section{To cite this version:}

Adem Lale, Nicolas Videau, Abdelhakim Bourennane, Frédéric Richardeau, Samuel Charlot. Analysis of the three-chip switching cells approach for integrated multi-phase power converter combining monolithic and hybrid techniques: Experimental validation on $\mathrm{SiC}$ and $\mathrm{Si}$ power assembly prototypes. Power Electronics and Applications (EPE'15 ECCE-Europe), 2015 17th European Conference on., Sep 2015, Genève, Switzerland. 10.1109/EPE.2015.7311711 . hal-01230267

\section{HAL Id: hal-01230267 \\ https://hal.science/hal-01230267}

Submitted on 18 Nov 2015

HAL is a multi-disciplinary open access archive for the deposit and dissemination of scientific research documents, whether they are published or not. The documents may come from teaching and research institutions in France or abroad, or from public or private research centers.
L'archive ouverte pluridisciplinaire HAL, est destinée au dépôt et à la diffusion de documents scientifiques de niveau recherche, publiés ou non, émanant des établissements d'enseignement et de recherche français ou étrangers, des laboratoires publics ou privés. 


\title{
Analysis of the three-chip switching cells approach for integrated multi- phase power converter combining monolithic and hybrid techniques: Experimental validation on $\mathrm{SiC}$ and $\mathrm{Si}$ power assembly prototypes
}

\author{
Adem Lale ${ }^{1,2}$, Nicolas Videau ${ }^{1,2}$, Abdelhakim Bourennane ${ }^{1,2}$, Frédéric Richardeau ${ }^{3}$, Samuel \\ Charlot $^{1}$ \\ ${ }^{1}$ CNRS, LAAS, 7 avenue du Colonel Roche, F-31400 Toulouse, France \\ ${ }^{2}$ University of Toulouse, UPS, LAAS, F-31400 Toulouse, France \\ ${ }^{3}$ University of Toulouse; INP, UPS; LAPLACE (Laboratoire Plasma et Conversion d'Energie) ENSEEIHT, 2 rue \\ Charles Camichel, BP 7122, F-31071 Toulouse cedex 7, France \\ CNRS; LAPLACE; F-31071 Toulouse, France
}

\section{Acknowledgements}

This research work received financial support from the French National Research Agency (ANR). The project name is "ConvPIUS", ANR-13-JS09-0008-01, using the technological support of RenatechLAAS and 3DPHI platforms. The authors are particularly grateful to Mr. Serge BONTEMPS, from Microsemi Power Modules, France, for providing power MOSFET and power diode Silicon dies.

\section{Keywords}

« Power hybrid integration », « Monolithic integration », «Packaging », « Commutation loop », « Stray inductance », « $\mathrm{SiC}$ power converter », « Insulated gate bipolar transistor (IGBT) », « 2D simulations »"

\begin{abstract}
In this paper, the authors present a novel integration approach for multi-phase IGBT module, based on both monolithic and hybrid integration methods. In this proposed "3-chip" approach, the discrete switches are integrated into three generic monolithic multi-pole power chips and assembled with a judicious packaging. This reduces significantly the commutation loop area and so the stray inductance responsible of overshoot voltage and common-mode dv/dt effect. The operating modes of the multipole chips were validated in an inverter application by 2D simulations under mixed-mode Sentaurus $^{\mathrm{TM}}$. In order to characterize the commutation loop of the 3-chip approach, two prototype power modules with different technologies ( $\mathrm{Si}$ and $\mathrm{SiC}$ dies) have been realized on PCB substrates. The stray inductances were measured using a precision impedance analyzer (frequency analysis). A double-pulse characterization was also performed to illustrate the effect of stray inductance reduction at the turn-off (temporal analysis). For comparison purposes, two "classical" power converters have been also realized and analyzed. According the results, measurements and analytic estimates, the proposed packaging design allows reducing the stray inductance by at least a ratio of two as compared to the classical layout.
\end{abstract}

\section{Introduction}

Power electronic modules constitute one of the driving forces towards modularization and integration of power electronic systems [1] [2]. For instance, commercial IGBT power modules include singlephase leg and three-phase inverter, which utilize two or six pairs of anti-paralleled IGBT and freewheeling diodes. The packaging technology of power modules is mainly based on wire-bond technology. Stray inductance is a major concern in the design of IGBT packages and power stages with both high switching speed and high power handling requirements. Stray inductance inside a module package includes the inductance of electrode, inductance due to bonding wires and inductance due to substrate pattern [2].

The domain of power hybrid integration aims at producing a power electronics which is more compact and more reliable. One solution consists in the reduction of the commutation loop stray inductance. 
Several contributions were reported for the stray inductance reduction. These approaches are based on the improvement in the structure of the package to reduce the parasitics of the module [1-4].

The proposed approach is an original concept in which the converter performance is improved through the integration both at the semiconductor level and at the power assembly level. Indeed, the power switches are judiciously integrated within three different monolithic power chips and a new assembly is devised so that to reduce the stray inductance of the commutation loop and its $\mathrm{dv} / \mathrm{dt}$ effect with respect to ground.

\section{Illustration of the proposed three-chip integration approach}

The proposed approach allows the realization of a multi-phase IGBT based converter using only three generic independent power chips (Fig. 1a) [5-8]. For the high-side, the IGBTs and diodes are monolithically integrated in a single multi-pole Common Anode power chip (Fig. 1e) [5]. This monolithic chip is based on the vertical integration of multiple Reverse Conducting IGBT (RC-IGBT) [9-11]. For the low-side, the IGBTs are monolithically integrated in a vertical single multi-pole power chip (Fig. 1c). Likewise, the diodes are monolithically integrated in another vertical single multi-pole power chip (Fig. 1d). The backside of the low-side power chips (multi-pole IGBT and multi-pole Diode power chips) are relatively thick $\mathrm{P}^{+}$substrates which allows one to envisage the use of dielectrically filled deep trenches [12-15] for insulation between IGBTs and between diodes that share the same N- drift region within each power chip.

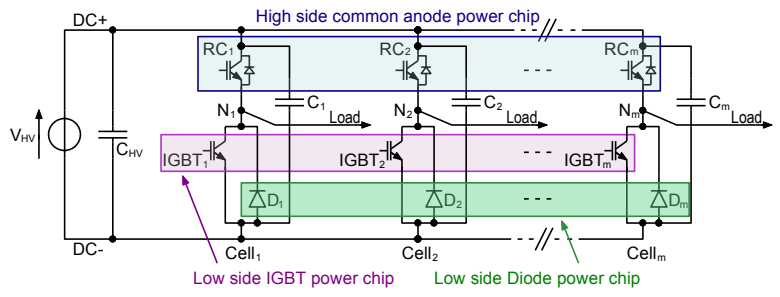

(a)

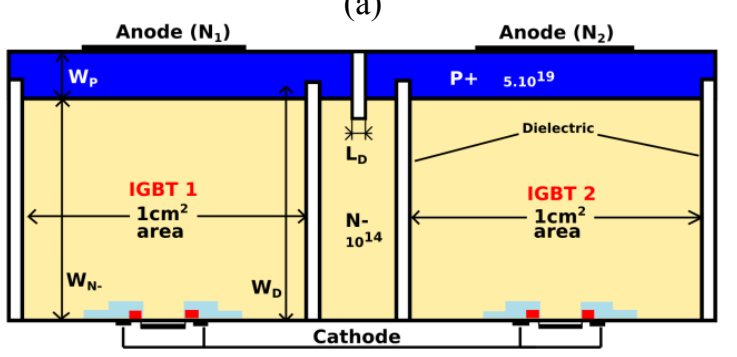

(c)

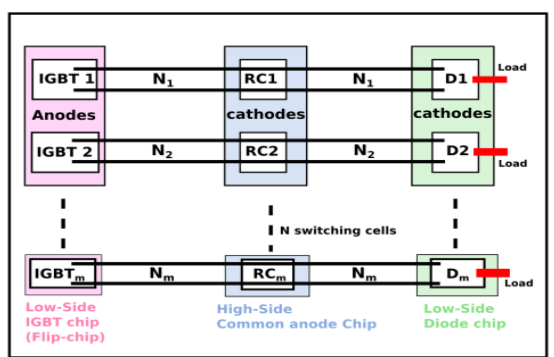

(b)

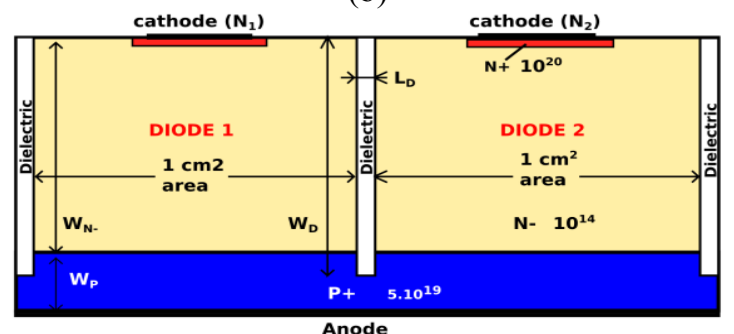

(d)

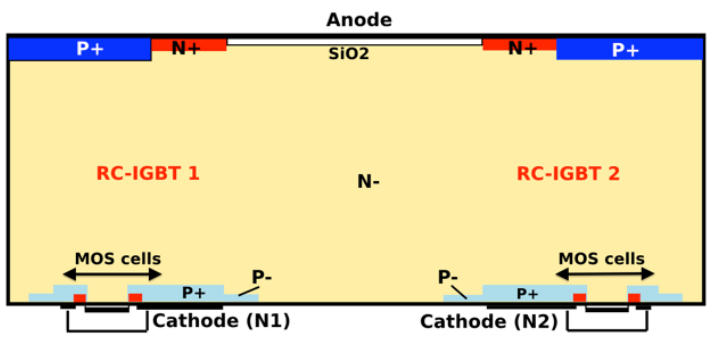

(e)

Fig. 1: (a) Three-chip integration approach, (b) top view of the targeted three-chip assembly for the multi-phase converter. Cross-sectional view of the proposed multi-pole power chips applied to an $\mathrm{H}$ bridge converter: (c) multi-pole IGBT chip, (d) multi-pole Diode chip and (e) multi-pole Common Anode chip (the concept of the Common Anode chip was already presented).

Concerning the packaging, the three chips are placed so that the stray inductance of the switching cell is minimized. This is possible by placing the low-side IGBT multi-pole chip on one side of the common anode multi-pole chip and the low-side diode chip on the other side of the common anode chip as shown in figure $1 \mathrm{~b}$. Based on the fact that the load connection is at the top of one of the two low-side chips, no high $\mathrm{dv} / \mathrm{dt}$ appears on the assembly substrate avoiding then any high frequency 
leakage current through this one. The combination of a low stray inductance and a low common-mode leakage current is an interesting issue when considering fast Si power devices and WBG components. It should be noted that the three-chip approach is a generic approach which can be easily extended to a power converter consisting of " $X$ "-phase. Thereby, the number of chips and the commutation loops remain unchanged as compared with the case of the H-bridge converter.

\section{Application of the proposed 3-chip integration approach for an H-bridge converter}

We study the three-chip approach in an H-bridge converter. To highlight the advantages brought by the 3-chip approach, two solutions are considered: the realization of a conventional H-bridge (Fig. 2a) and the realization of a 3 -chip based H-bridge (Fig. 2b).

The conventional H-bridge uses four RC-IGBTs. For the validation of the 3-chip approach on an Hbridge, we use one Common Anode chip for the high-side but, for the low-side we use two discrete IGBTs and two discrete diodes. Common Anode chip, RC-IGBTs and IGBTs were realized in our micro and nanotechnology platform and characterized [5].

The operating modes of the three monolithic multi-pole power chips and their association within an $\mathrm{H}-$ bridge converter have been studied by $2 \mathrm{D}$ simulations. The results are presented in the following section.

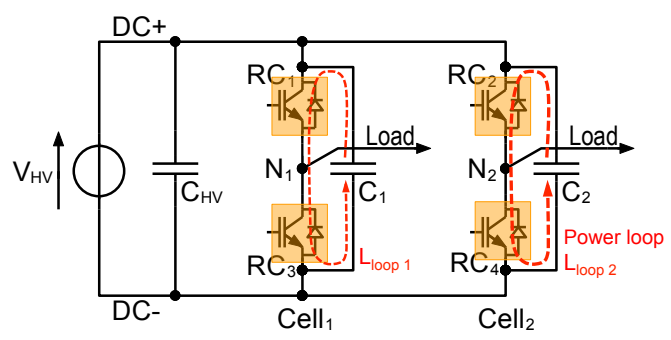

(a)

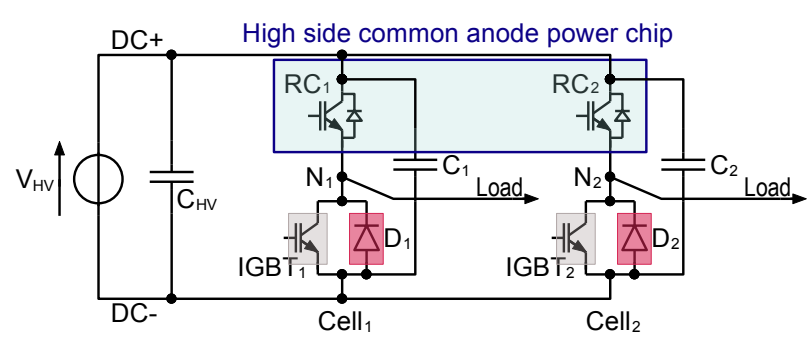

(b)

Fig. 2: (a) Conventional H-bridge, (b) 3-chip based H-bridge.

\section{Validation of the three-chip based H-bridge by 2D simulations}

Sentaurus $^{\mathrm{TM}} 2 \mathrm{D}$ simulations were carried-out in order to validate the operating modes of the monolithic power chips. The operating modes of the common anode chip were already validated in previously reported works [5]. So we will focus on the operating modes of the two new monolithic multi-pole structures composed of IGBTs or diodes. We validated their operating modes separately in a simplified switching circuit. The simulation conditions and results are presented hereafter. It should be noted that in these two multi-pole monolithic structures, the active area of each section is of $1 \mathrm{~cm}^{2}$ (see Fig. 1c and Fig. 1d).

Table I. Geometrical parameters used for 2D simulations of multi-IGBT chip and multi-diode chip

\begin{tabular}{cccc}
\hline \hline Parameters & Description & Value $(\boldsymbol{\mu m})$ \\
\hline & & IGBTs chip & Diodes chip \\
$\mathrm{W}_{\mathrm{N}^{-}}$ & $\mathrm{N}_{\text {drift }}$ thickness & 140 & 200 \\
$\mathrm{~W}_{\mathrm{D}}$ & Trench depth & 180 & 240 \\
$\mathrm{~L}_{\mathrm{D}}$ & Trench width & 70 & 40 \\
\hline \hline
\end{tabular}

\section{Common cathode multi-IGBT power chip}

This structure has three electrodes: two anode electrodes and one cathode electrode which is common for the two IGBT sections. In this inverter application, when one section is in ON-state, the other adjacent section is in OFF-state. So, this structure must support the applied anode1-anode 2 voltage. Insulation between the two IGBT sections is achieved by dielectrically (oxide for 2D simulations) filled trenches that are placed between the IGBT sections. The simulation conditions are the following: a $600 \mathrm{~V}$ DC voltage is applied between the anode electrodes and a DC current supply of $100 \mathrm{~A} / \mathrm{cm}^{2}$ is 
connected to the common cathode electrode. The left IGBT section is in ON-state with a gate bias of $15 \mathrm{~V}$, the right IGBT section is in OFF-state with the gate-to-cathode voltage being set at $0 \mathrm{~V}$. Figure $3 \mathrm{a}$ shows the current density distribution in ON-state IGBT section. Figure $3 \mathrm{~b}$ shows the equipotential lines in OFF-state IGBT section. We can see that the right section is in OFF-state and a space charge expands in the $\mathrm{N}^{-}$region between the dielectrically filled trenches. The leakage current in the OFFstate section is about $46 \mu \mathrm{A}$. The used trench depth in simulations is of $180 \mu \mathrm{m}$.

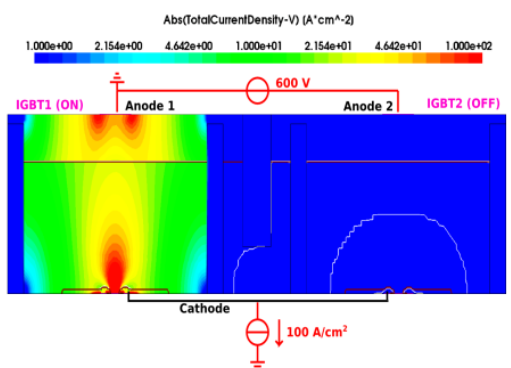

(a)

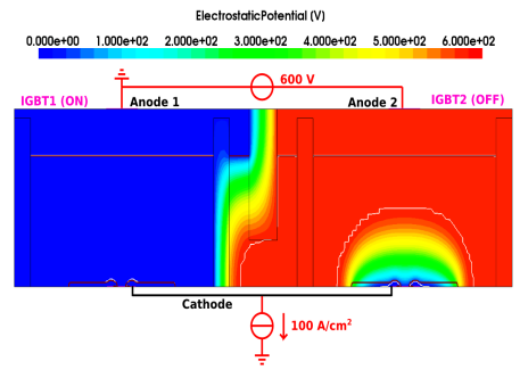

(b)

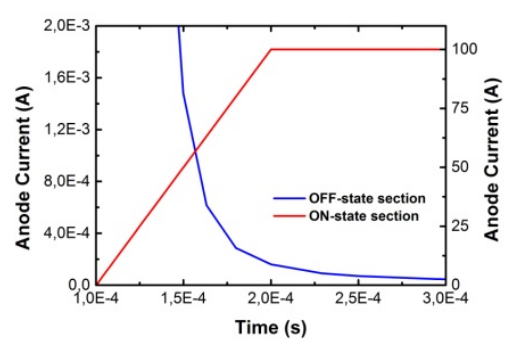

(c)

Fig. 3: (a) Distribution of current density, (b) equipotential lines distribution, (c) leakage current in OFF-state section.

\section{Common anode multi-PiN-diode power chip}

This structure has also three electrodes: two cathode electrodes at the top side and one anode electrode common to the two diode sections at the backside. This structure was chosen because it enables a direct top-to-top side connection with the common anode chip by means of one wire-bonding link without a flipping operation. This structure must support the applied voltage between the two cathode electrodes. To validate the operating modes, simulation conditions are the same as previously: a $600 \mathrm{~V}$ DC voltage is applied between the cathode electrodes and a DC current supply of $100 \mathrm{~A} / \mathrm{cm}^{2}$ is connected to the common anode electrode.

Figure 4a shows the distribution of current density in ON-state section of the multi-diode chip. Figure $4 \mathrm{~b}$ shows the equipotential lines in OFF-state section of the multi-diode chip. We can see that the right diode section is reverse biased and space charge expands mainly in the $\mathrm{N}^{-}$region. The leakage current in OFF-state section is about $2.7 \mu \mathrm{A}$. The trench depth used in simulations is of $240 \mu \mathrm{m}$.

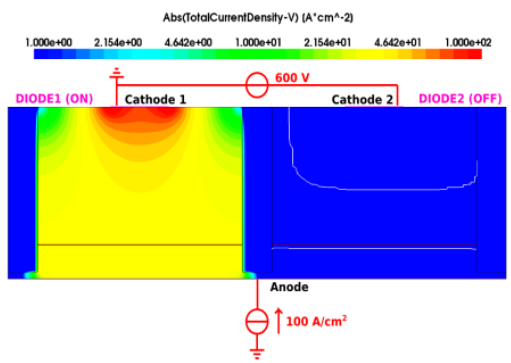

(a)

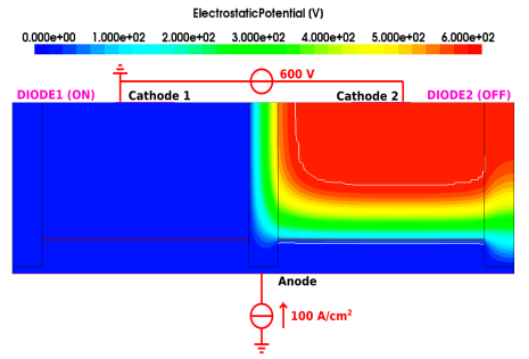

(b)

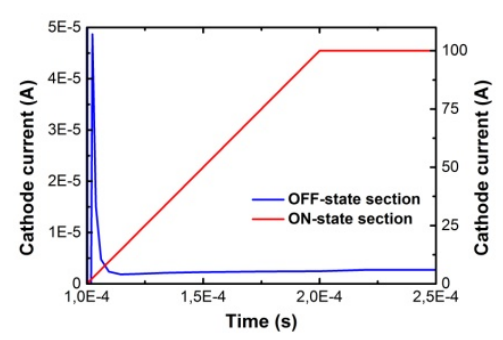

(c)

Fig. 4: (a) Distribution of current density, (b) equipotential lines distribution, (c) leakage current in OFF-state section.

\section{H-bridge converter}

Once the operating modes of the two monolithic structures have been validated, we associated them with the common anode chip to realize an H-bridge chopper as shown in Figure $2 \mathrm{~b}$. The results are shown in figure 5. A 100 A DC-current source is inserted between the switching cells. A $600 \mathrm{~V}$ DCvoltage source is applied between the anode electrode of the common anode chip and the cathode electrode of the multi-pole IGBT chip. The IGBTs are controlled using a dead time of $1 \mu \mathrm{s}$. 


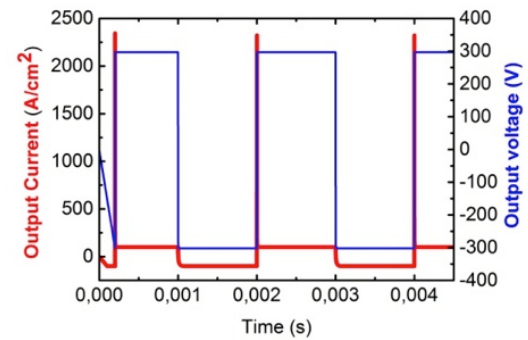

(a)

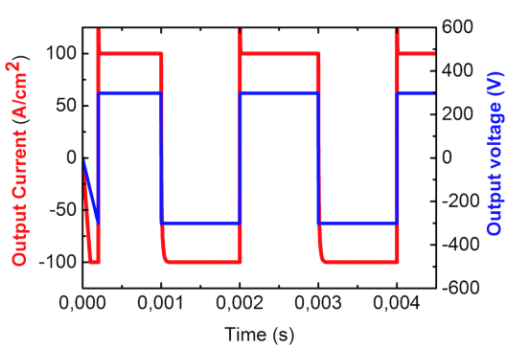

(b)

Fig. 5: (a) Simulated inverter circuit resulting from the association of the three monolithic chips, (b) zoom on switching phase.

\section{Packaging for the proposed 3-chip concept}

\section{Description of the power modules: conventional H-bridge and 3-chip H-bridge}

For the purpose of comparing and validating our optimization approach, two layouts of power converters were envisaged. The two converter versions are generic and can host power chips of different sizes and of different technologies ( $\mathrm{Si}, \mathrm{SiC})$.

The first layout corresponds to the conventional converter, while the second layout corresponds to the proposed "3-chip" concept. Both converters were designed so that they can be realized in a power module. However, for validating this study, we realized/transposed our converters on a one-layer PCB substrate. The thermal aspect is not taken into account in this study. If one wants to design the converters only on a PCB substrate, he could preferably use a two-layer in order to obtain better commutation cells.

The conventional converter that uses four RC-IGBTs is given in figure 6a. A general view of the PCB with the control environment is given in figure $6 \mathrm{c}$. With this conventional approach, the commutation loops are of equal length and coplanar with the PCB (Fig. 6b). The surface of the commutation loop is $130 \mathrm{~mm}^{2}$.

For validating the 3-chip concept, a converter obtained by assembling a common anode chip, two IGBT chips and two PiN diode chips (see $\S$ III) is designed as shown in figure 6d. Within one "commutation leg", this approach decouples the functions of the diode and the IGBT. Therefore, the commutation loop of a single "leg" is divided into two loops. One loop « $\mathrm{L}_{\mathrm{Loop}}$ IGBT » and one loop « $\mathrm{L}_{\text {Loop }}$ diode », of equal lengths and distributed on both sides of the central common anode chip (Fig. 6d). The decoupling capacitor $C_{m}$ of the same leg is equally divided between the decoupling capacitance associated with the IGBT $\mathrm{C}_{\mathrm{m}, \mathrm{IGBT}}$, and the decoupling capacitance associated with the diode $\mathrm{C}_{\mathrm{m} \text {,diode }}$ (Fig. 6g). The commutation loops are orthogonal to the PCB (Fig. 6e) and are greatly lower than the conventional layout [17]. A general view of the printed circuit board is given in figure 6f. The new assembly based on the three-chip approach permits to reduce the surface and hence the length of the commutation loop. This leads to a reduction in the stray inductance of the commutation loop. Indeed, the areas of the loops « $\mathrm{L}_{\text {Loop }}$ IGBT » and « $\mathrm{L}_{\text {Loop }}$ diode » are almost five times shorter than the conventional « $\mathrm{L}_{\text {Loop }}$ " (area $\mathrm{L}_{\text {loop }} \mathrm{IGBT}=$ area $\mathrm{L}_{\text {loop }}$ Diode $=26 \mathrm{~mm}^{2}$ ). Stray inductance reduction permits to reduce losses during switching as well as voltage overshoot across power switches.

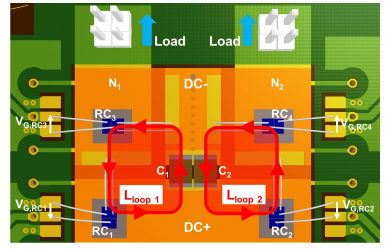

(a)

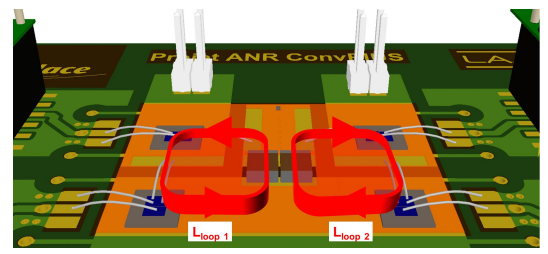

(b)

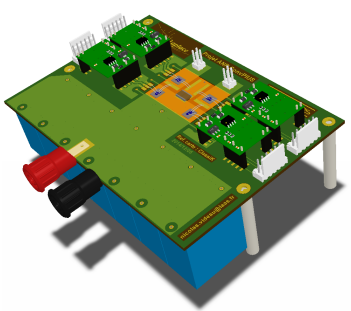

(c) 


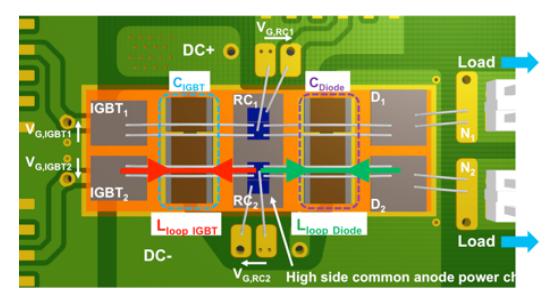

(d)

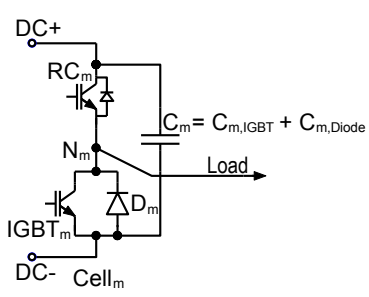

Switching cell

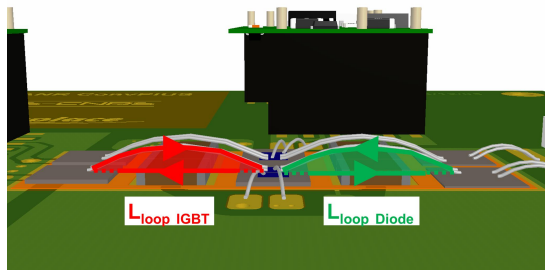

(e)

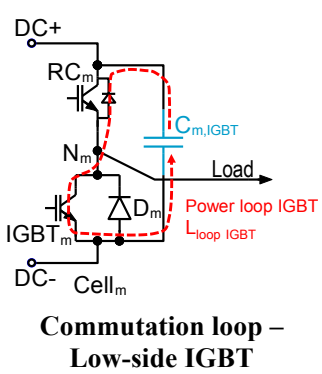

(g)

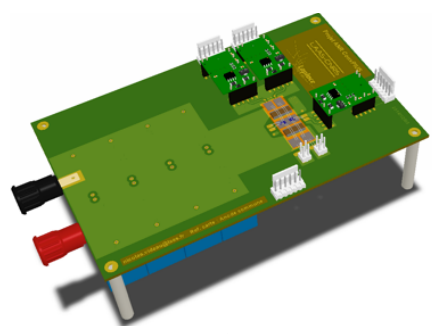

(f)

Fig. 6: (a) Top view of the conventional H-bridge and (b) coplanar power commutation loops, (c) design of the classical H-bridge in PCB version. (d) Top view of the three-chip based H-bride and (e) orthogonal power commutation loops, (f) design of the three-chip based H-bridge in PCB version, (g) switching cell decomposed into two commutation loops.

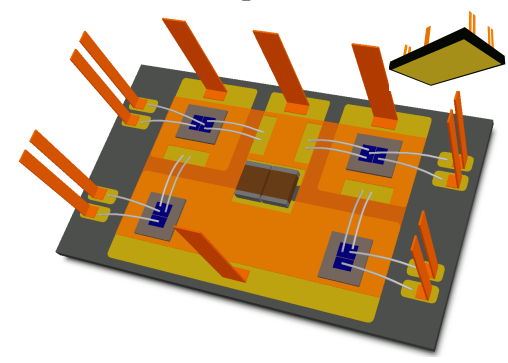

(a)

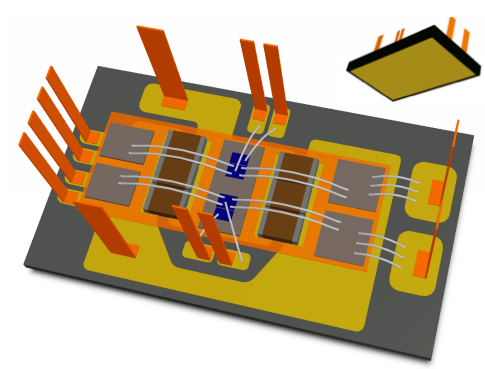

(b)

Fig. 7: (a) Power module version of the conventional H-bridge, (b) power module version of the three-chip based H-bridge.

\section{Assembly}

This section describes the followed procedure for the realisation of the different converters. To that end, we consider the 3-chip converter that makes use of SiC chips. The assembling steps are the same for each of the other converters. The Kapton polyimide film is cut and windows, realized in the film, wider than the decoupling capacitor allow mounting this latter on the PCB, but smaller than the power chips for positioning the chips and to have access to the contacts (flipped chips and non flipped). The kapton film behaves as a passivation for flipped chips. The kapton film is first cut using laser and the following steps are summarized in table II for the case of a converter that uses SiC power chips. It should be noted that the procedure is generalizable.

The advantages of this solution are:

- Easy to implement, robust, and industrializable,

- Placement of the chips (in x/y),

- Height control,

- Flip-chip of the chips. 
Table II. Description of the steps for assembly

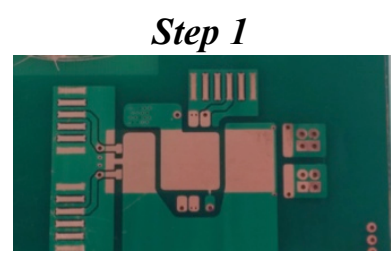

Kapton film cut using laser (Laser $\quad \mathrm{CO}_{2}$ FineMarkerHybrid

Trotec). Used insulation film: Kapton double-sided acrylic (Kapton $75 \mu \mathrm{m}$ ARclad 7876 Adhesives Research).

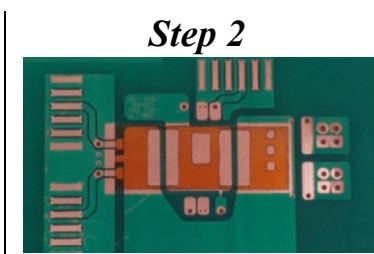

Kapton positioning on the PCB.

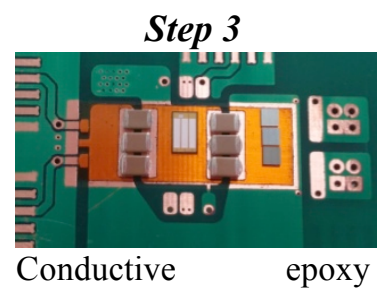

(EpoTek H20E) and positioning of power chips and capacitors. Placed in an air-oven $\left(80-90^{\circ} \mathrm{C} / 2 \mathrm{~h} 30-3 \mathrm{~h}\right)$.

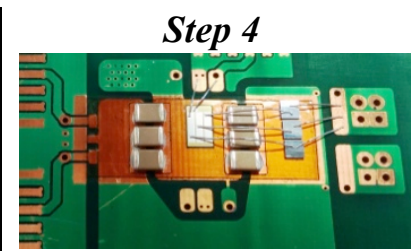

Wire bonding: $25 \mu \mathrm{m}$ (Gate) and $250 \mu \mathrm{m}$ (DrainSource).

\section{Modeling of an elementary commutation loop at turn-off}

We consider the case of a fast and hard switching to turn-off, obtained using a very small external gate resistance (or close to zero) that gives birth to a negligible Miller effect in time duration (disappearance of Miller plateau) [16]. In these conditions, the driver output voltage is quasi-directly applied to the gate MOSFET (remains only the polysilicon gate resistance and the driver's output resistance). Therefore, the MOS channel current decreases to zero before the voltage starts to rise significantly across the MOSFET (i.e sequence of $\mathrm{dV}_{d s} / \mathrm{dt}$ ) and the equivalent parasitic capacitance seen between the drain and the source is given by $\mathrm{C}_{o s s}=\mathrm{C}_{d s}+\mathrm{C}_{g s}$. The free wheeling diode starts to conduct as soon as $\mathrm{C}_{\text {oss }}$ is fully charged. Therefore, the commutation loop at turn-off of the controlled switch can be modelled by the following schematics:

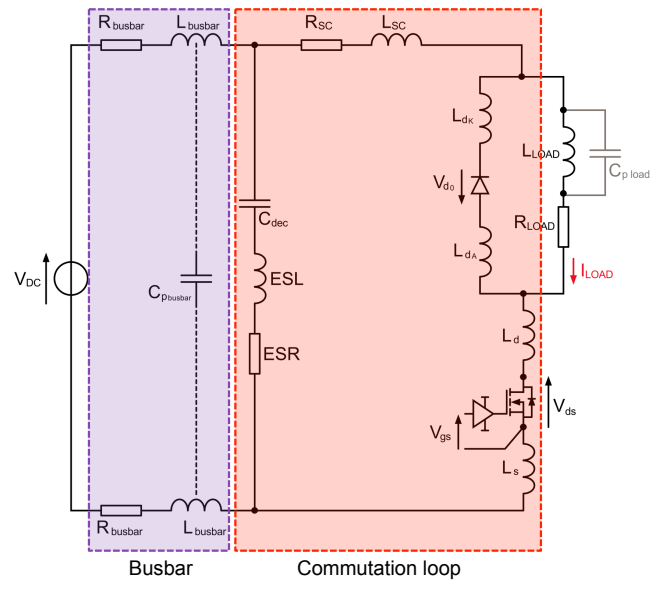

(a)

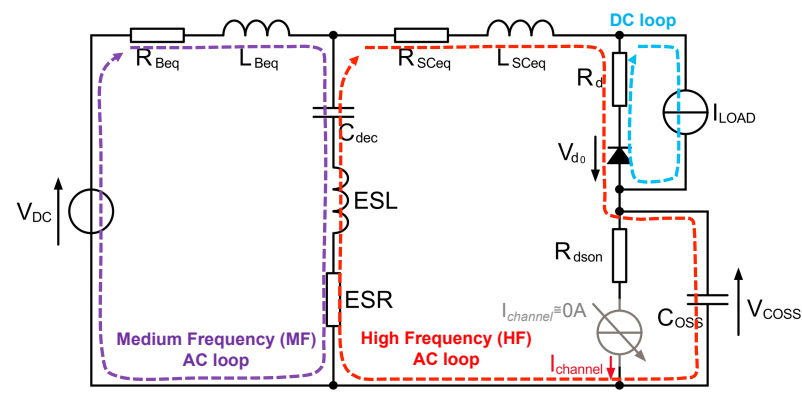

(b)

Fig. 8: (a) Modeling of the switching cell with parasitic components and (b) its equivalent diagram at turn-off.

Therefore, the total maximum overshoot voltage across the switch can be obtained by summing up the terms of overvoltage that appear in Fig. 8b):

$$
\delta V c_{\text {ossMAX }}=I_{\text {load }} \sqrt{\frac{L_{\text {Beq }}}{C_{\text {dec }}}}+K I_{\text {load }} \sqrt{\frac{L_{S C e q}+E S L}{C_{\text {oss }}}}+V_{\text {diode }}+\left(L_{S C e q}+E S L\right) \frac{d i_{\text {channel }}}{d t}
$$

According to this equation, we can see the different terms associated to the commutation loop. Terms a) and b) deals with the effect of the storage energy in the stray inductance of the busbar and the stray inductance of the switching cell on the overvoltage across $\mathrm{C}_{d e c}$ and $\mathrm{C}_{\text {oss }}$. The first one is low and at 
medium frequency $(<5 \mathrm{MHz})$ while the second is predominant more and more with WBG chips that exhibit low capacitance. $\mathrm{cm}^{2}$ values compared to $\mathrm{Si}$ devices and so a high frequency oscillation $(>50 \mathrm{MHz})$. In term b), $\mathrm{K}$ represents the factor of current sharing between $\mathrm{C}_{\text {oss }}$ and $\mathrm{C}_{\mathrm{T}_{\text {diode }}}$. Term $\mathrm{c}$ ) describes the dynamic forward recovery at the turn-on of the diode, especially for Si PIN diode. Finally, term d) represents the effect of a residual channel current through the switching loop if a significant Miller effect is realized. In summary, for integrated and fast converter, the ratio $\mathrm{ESL}_{X} / \mathrm{C}_{X}$ must be minimised in order to reduce oscillations. A reduction in $\mathrm{C}_{X}$ must be accompanied by a reduction of $\mathrm{ESL}_{\mathrm{X}}$ in the same proportion.

\section{Method for the characterization in time domain of the commutation cell at turn-off}

A frequency domain modeling approach based on the decomposition into constitutive elements (set of wire bonds, decoupling capacitor and filtering, busbar, PCB...) was realised by means of an Agilent 4294A impedance analyzer associated to a coaxial compensated probe 42941A dedicated for measurements on a PCB. The results will not be presented in detail in this paper. Only the measurement values will be provided for comparison purposes with the temporal analysis approach (which is described in this section).

In order to highlight the oscillations at power device turn-off, we tested the converters (conventional as well as proposed) using the classical double pulse method. This circuit is generally used for the characterisation of overvoltage phenomena at turn-off. The principle consists in controlling the phase leg with two pulses. The first pulse allows current installation, the second one, which is smaller and closer to an ideal impulse, permits the excitation of the commutation cell in order to obtain the oscillations.

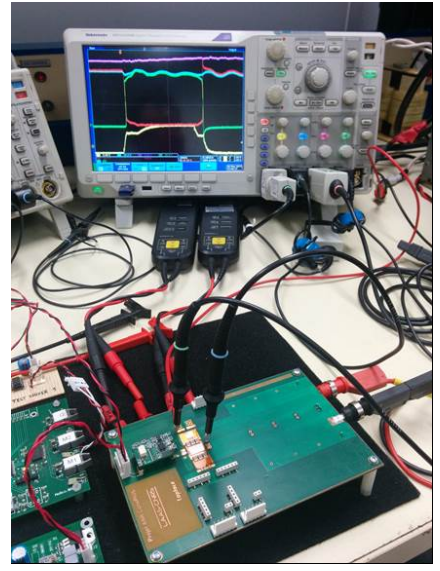

(a)

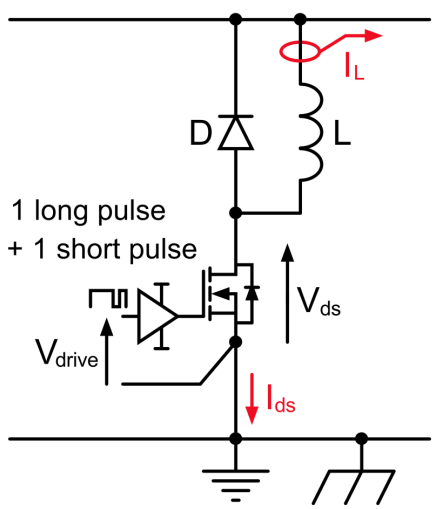

(b)

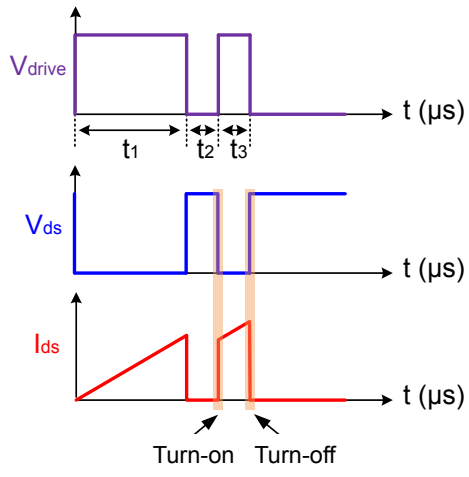

(c)

Fig. 9: (a) Test bench for devices switching characterization, (b) test circuit in Buck-Type topology, (c) control signals of the "double-short pulse" method (Oscilloscope TEK DPO4104B 1GHz/5GSamp.s ${ }^{-1}+$ Passive voltage probes TPP1000 $1 \mathrm{GHz}$ Deskew mode + Hi/Average x4 mode).

In this paper, the characterization of the commutation loops of the previously presented assemblies (see Fig. 6) focus on the analysis of the voltage waveform across one of the transistors (between drainkelvin and source-kelvin) at turn-off. The lower side transistor is preferred because it allows eliminating measurements perturbation by the effect of the involved common mode voltage. The analysis of the components constituting the amplitude and frequency of the voltage waveform enable us to extract the physical parameters characterising the quality of the commutation cell. According to equation 1, two main temporal components are involved: the first one is called HF allows to characterize the couple $\left(\mathrm{L}_{S C e q}, \mathrm{C}_{\text {oss }}\right)$, the second one called MF allows to characterize the couple $\left(\mathrm{L}_{B e q}\right.$, $\mathrm{C}_{\text {dec }}$ ).

This methodology will be applied to two groups of converter boards. One group corresponds to an assembly called "conventional" and uses two chips mounted on the backside and wired using two sets of wire bonds (cf. Table III): case 1.1) (silicon version) and case 1.2) (full-SiC version). A second group corresponds to an assembly equivalent to the thee-chip approach detailed in § II of this paper. In this "proposed" assembly, one of the two chips of the commutation cell is mounted using flip-chip 
technique and wired using a single set of wire bonds (cf. Table IV): case 2.1) (silicon version) and case 2.2) (full-SiC version). One of the main objectives of these measurements is to compare the assembly types and mainly the interconnection of the chips.

Table III. Characterization of "conventional" Si and SiC power converters

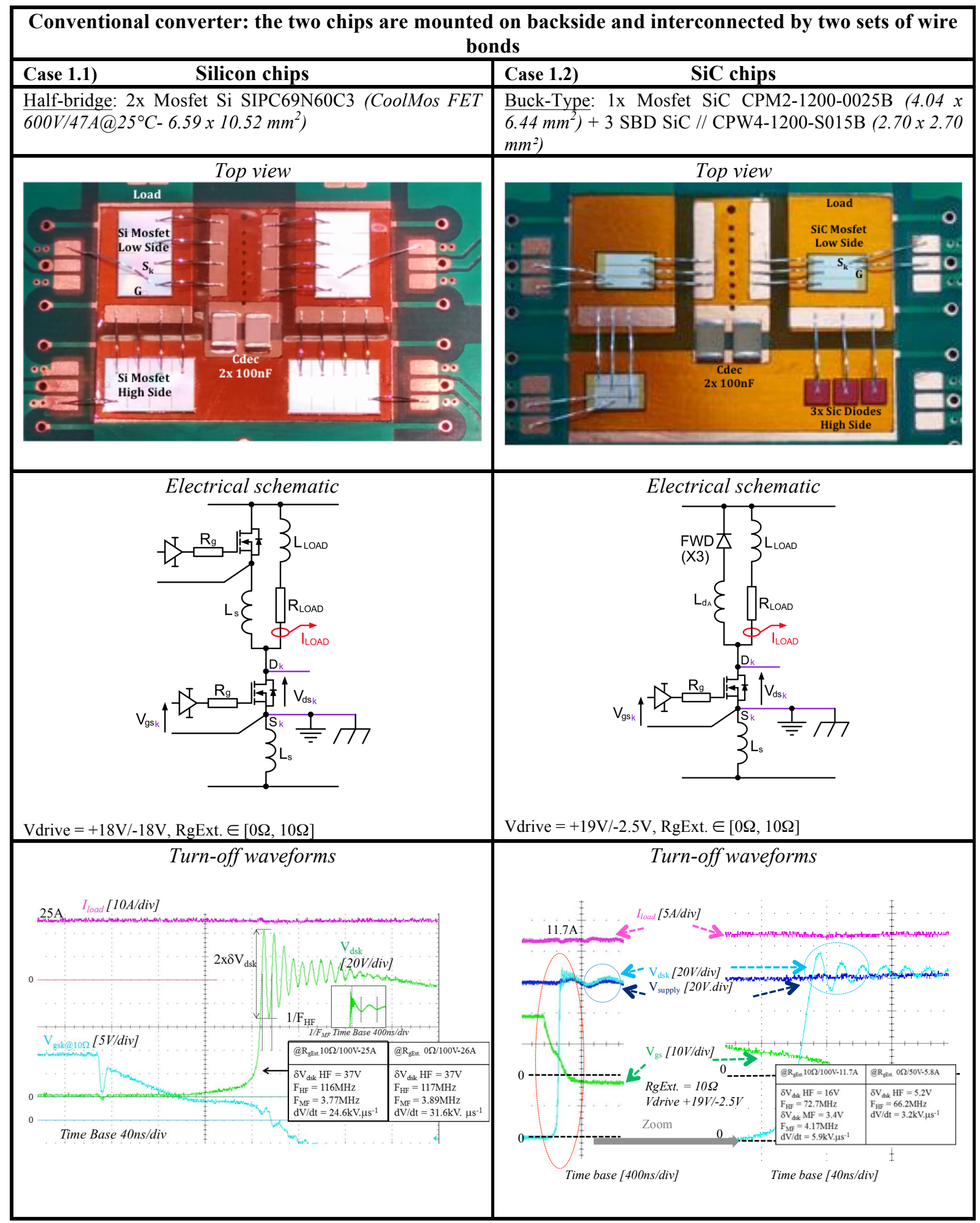


Table IV. Characterization of "proposed" Si and SiC power converters

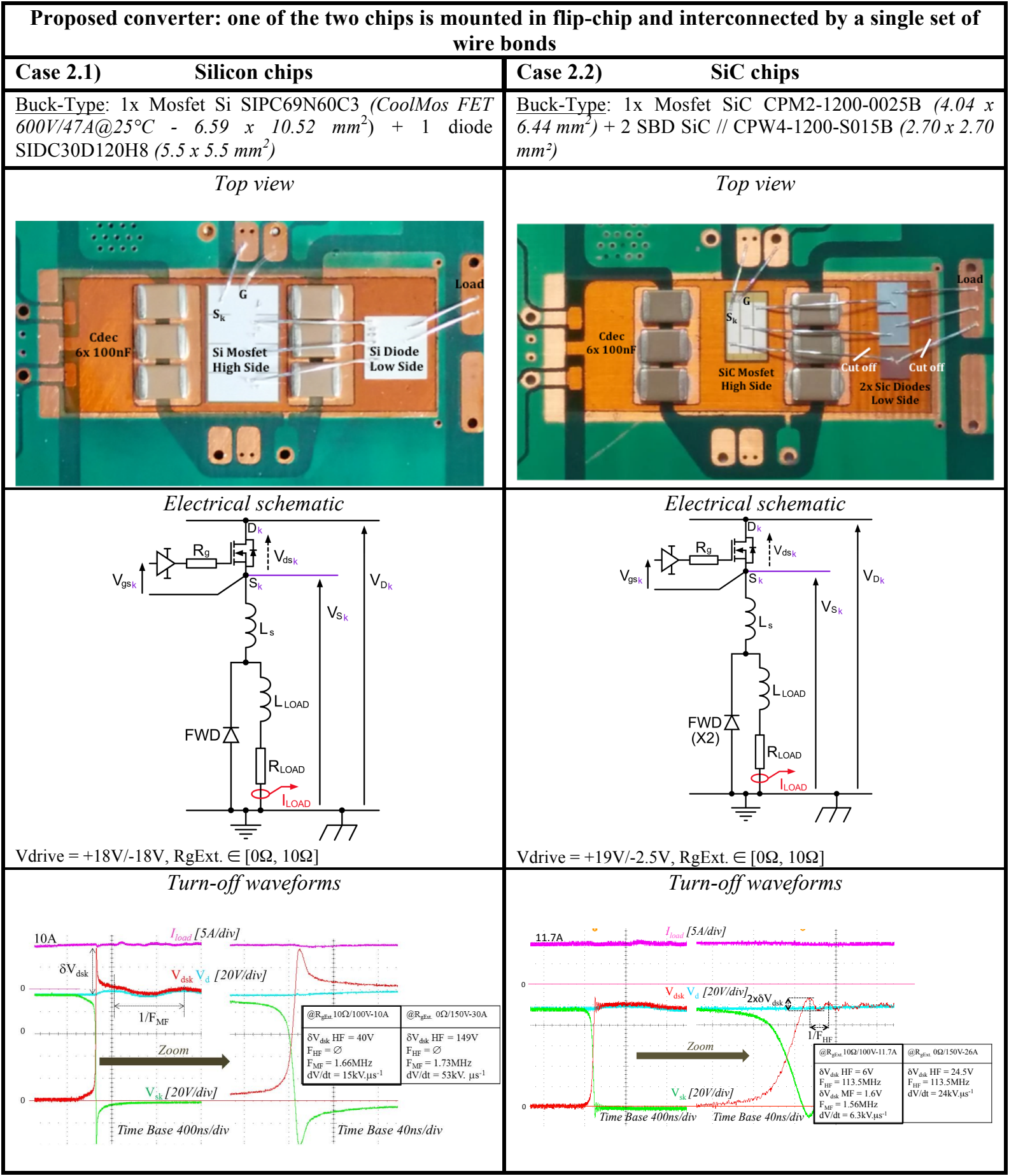

Frequency analysis with impedance analyzer and probe has allowed realizing distinct and reproducible measurements on the commutation loops. These results are considered as reference results (Table V). The results show that the optimized commutation loop is at least twice less inductive than the classic loop. This gain allows to increase the safety margin (SOA) and the reliability level, and to reduce the overshoot across the power devices, the turn-off losses and EMI emission. Integration of both decoupling and filtering capacitors with chips allow to reduce strongly stray inductances values, compared to a power module (type IPM internal stray $>20 \mathrm{nH}$ ). The optimized commutation loop can be further improved with a better thermal substrate combined to a volumic passivation, allowing to minimize the distance between the chips and so the length of interconnections.

Two methods of extraction of the stray inductance values have been proposed: the first a) based on the peak value of the first HF voltage oscillation, the second b), based on a) and combining the $\mathrm{dV}_{\text {coss }} / \mathrm{dt}$ 
expression, finally c) based on the time period of the oscillation. For now, the damping factor is not considered. So, one can demonstrate that method a) gives lower bound values whereas method c) gives upper bound values. Method c) is more easy and accurate to implement, and gives more coherent results as compared to the impedance analyser measurements.

Table V. Stray inductance value: comparison between measured and analytic estimated values

\begin{tabular}{|c|c|c|c|c|c|c|}
\hline \multirow[b]{3}{*}{$\begin{array}{c}\text { Equivalent } \\
\text { loop } \\
\text { inductances } \\
\text { on busbar } \\
\text { stage and } \\
\text { switching } \\
\text { cell stage }\end{array}$} & \multicolumn{3}{|c|}{$\begin{array}{c}\text { Medium-frequency busbar-loop characterization } \\
\text { (equivalent localized physical quantities: } \mathrm{L}_{\mathrm{beq}}, \mathrm{C}_{\mathrm{dec}} \text { ) }\end{array}$} & \multicolumn{3}{|c|}{$\begin{array}{l}\text { High-frequency switching-cell loop characterization } \\
\text { (equivalent localized physical quantities: } \mathrm{L}_{\text {sceq }}, \mathrm{ESL}_{\mathrm{dec}}, \mathrm{C}_{\mathrm{oss}} \text { ) }\end{array}$} \\
\hline & Measured values & \multicolumn{2}{|c|}{ Analytic estimated values } & Measured values & \multicolumn{2}{|c|}{ Analytic estimated values } \\
\hline & $\begin{array}{l}\text { 1) Frequential 100MHz } \\
\text { Impedance Analyzer } \\
\text { Agilent } 4294 \mathrm{~A}+\text { dedicated } \\
\text { PCB Probe } 42941 \mathrm{~A} \\
\\
\text { 2) Capacimeter Agilent } \\
\text { B1505a } \\
\\
\text { 3) Temporal analysis } \\
\text { oscilloscope TEK } \\
\text { DPO4104B } \\
\text { 1GHz/5GSamp. } \mathrm{s}^{-1}+ \\
\text { Passive voltage probes } \\
\text { TPP1000 } 1 \mathrm{GHz} \text { (Deskew } \\
\text { mode + Hi/Average } \mathrm{x} 4 \\
\text { mode) }\end{array}$ & \multicolumn{2}{|c|}{$\begin{array}{l}\text { a) From the voltage ripple } \\
\text { (damping neglected } \rightarrow \text { giving a lower } \\
\text { bound value): } \\
L_{\text {beqMIN }}=C_{\text {dec }}\left(\frac{\delta V_{\text {Cdec }}}{I_{\text {load }}}\right)^{2} \\
\text { b) From the oscillation period } \\
\text { (damping neglected } \rightarrow \text { giving a upper } \\
\text { bound value) : } \\
L_{b e q M A X}=\frac{1}{C_{d e c} \cdot\left(2 \pi \cdot F_{M F}\right)^{2}}\end{array}$} & $\begin{array}{l}\text { 1) Frequential } 100 \mathrm{MHz} \\
\text { Impedance Analyzer } \\
\text { Agilent } 4294 \mathrm{~A}+\text { dedicated } \\
\text { PCB Probe } 42941 \mathrm{~A} \\
\text { 2) Capacimeter Agilent } \\
\text { B1505a } \\
\\
\text { 3) Temporal analysis } \\
\text { oscilloscope TEK } \\
\text { DPO4104B } \\
1 \mathrm{GHz} / 5 \mathrm{GSamp} . \mathrm{s}^{-1}+ \\
\text { Passive voltage probes } \\
\text { TPP1000 } 1 \mathrm{GHz} \text { (Deskew } \\
\text { mode + Hi/Average } \mathrm{x} 4 \\
\text { mode) }\end{array}$ & \multicolumn{2}{|c|}{ 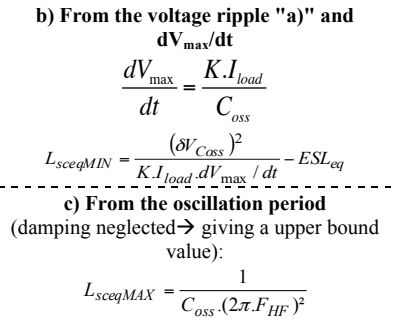 } \\
\hline $\begin{array}{l}\text { 1.1) } \\
\text { Classic Si } \\
\text { (Half-Bridge) } \\
2 x \text { Mosfet Si } \\
\text { SIPC69N60C3 } \\
\text { (data \& measures) } \\
\mathrm{C}_{\mathrm{oss}} @ 100 \mathrm{~V}=300 \mathrm{pF} \\
\mathrm{C}_{\mathrm{oss}} @ 150 \mathrm{~V}=220 \mathrm{pF} \\
\rightarrow \mathrm{K}=0.5\end{array}$ & \multirow[t]{2}{*}{$\begin{array}{l}\text { Cdec : 2xKEMET-X7R - } \\
500 \mathrm{~V} \text { Ref.C1812V104 } \\
\text { (measures) } \\
2 \times 60 \mathrm{nF} @ 100 \mathrm{~V} \\
2 \times 45 \mathrm{nF} @ 150 \mathrm{~V} \\
\mathrm{ESL}=0.8 \mathrm{nH} \\
\mathrm{ESL}_{\mathrm{eq}}=0.4 \mathrm{nH} \\
\mathrm{C}_{\text {filter (fp) }}: \mathrm{EPCOS} \\
\mathrm{B} 32654 \mathrm{~A} 4335 / 2 \times 3.3 \mathrm{uF} / \\
400 \mathrm{~V} / \mathrm{ESL} \mathrm{eqMAx}_{\mathrm{eqM}}=9 \mathrm{nH}\end{array}$} & $\begin{array}{l}L_{b e q M I N}= \\
13.5 n H\end{array}$ & $\begin{array}{l}L_{\text {beq } M A X}= \\
14.6 n H\end{array}$ & $\begin{array}{c}9.5 \mathbf{n H} \\
\text { (Extrapolated value) } \\
@ 10 \mathrm{MHz} \\
(4 \text { Win } 2 \text { x series) }\end{array}$ & $\begin{array}{l}\text { a) } 26 \mathrm{~A} / 100 \mathrm{~V} / \\
\mathrm{RgExt} .0 \Omega / \delta \mathrm{V}_{\text {Coss }}= \\
37 \mathrm{~V}-\mathbf{b}) \\
25 \mathrm{~A} / 100 \mathrm{~V} / \mathrm{RgExt} .10 \\
\Omega / 31.6 \mathrm{kV} \cdot \mathrm{\mu s}^{-1} \\
\\
\boldsymbol{L}_{\text {sceq } M I N}= \\
2.4 \mathbf{n H}- \\
4.4 \mathrm{nH}\end{array}$ & 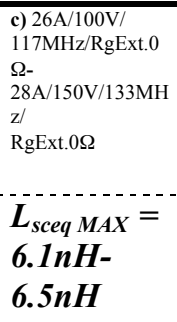 \\
\hline $\begin{array}{l}\text { 1.2) } \\
\text { Classic SiC } \\
\text { (Buck-Type) } \\
\text { 1x Mosfet SiC } \\
\text { CPM2-1200-0025B + } \\
\text { 3x SBD SiC // } \\
\text { CPW4-1200-S015B } \\
\text { (data sheet) } \\
\mathrm{C}_{\text {oss }} @ 100 \mathrm{~V}=470 \mathrm{pF} \\
\mathrm{C}_{\text {Tdiode }} @ 100 \mathrm{~V}= \\
3 \times 170 \mathrm{pF} \\
\rightarrow \mathrm{K}_{100}=0.48 \\
\end{array}$ & & $\begin{array}{l}\text { a) } 11.7 \mathrm{~A} / 100 \mathrm{~V} / \\
\mathrm{RgExt} . \\
10 \Omega / \delta \mathrm{V}_{\mathrm{Cdec}}= \\
3.4 \mathrm{~V} \\
\boldsymbol{L}_{\text {beq } M I N}= \\
\text { 10.2nH }\end{array}$ & $\begin{array}{l}\text { b) } 11.7 \mathrm{~A} / 100 \mathrm{~V} / \\
\text { RgExt. } \\
10 \Omega / 4.2 \mathrm{MHz} \\
\boldsymbol{L}_{\text {beq } \boldsymbol{M A X}}= \\
\boldsymbol{1 1 . 9 n \boldsymbol { H }}\end{array}$ & $\begin{array}{c}10.7 \mathrm{nH} \\
\text { @10MHz } \\
\text { (3Win } 2 \times \text { series) }\end{array}$ & 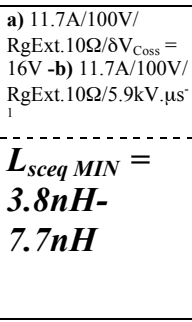 & $\begin{array}{l}\text { c) } 11.7 \mathrm{~A} / 100 \mathrm{~V} / \\
72.7 \mathrm{MHz} / \mathrm{RgExt} .1 \\
0 \Omega \\
\boldsymbol{L}_{\text {sceq } \boldsymbol{M A X}}= \\
10.2 \mathrm{nH}\end{array}$ \\
\hline $\begin{array}{l}\text { 2.1) } \\
\text { Proposed Si } \\
\text { (Buck-Type) } \\
1 \mathrm{x} \text { Mosfet Si } \\
\text { SIPC69N60C3 + 1x } \\
\text { diode } \\
\text { SIDC30D120H8 } \\
\text { (data \& measures) } \\
\mathrm{C}_{\text {oss }} @ 100 \mathrm{~V}=300 \mathrm{pF} \\
\mathrm{C}_{\text {Tdiode } @ 100 \mathrm{~V}=65 \mathrm{pF}} \\
\rightarrow \mathrm{K}_{100}=0.82 \\
\end{array}$ & $\begin{array}{l}\text { Cdec : 6xKEMET-X7R - } \\
500 \mathrm{~V} \text { Ref.C1812V104 } \\
\text { (measures) } \\
6 \mathrm{x} 60 \mathrm{nF} @ 100 \mathrm{~V} \\
6 \mathrm{x} 45 \mathrm{n} \mathrm{n} @ 150 \mathrm{~V} \\
\mathrm{ESL}=0.8 \mathrm{nH} \\
\mathrm{ESL}_{\mathrm{eq}}=0.14 \mathrm{nH} \\
\mathrm{C}_{\text {filter (fp) }}: \mathrm{EPCOS} \\
\mathrm{B} 32654 \mathrm{~A} 4335 / 2 \times 3.3 \mathrm{uF} / \\
400 \mathrm{~V} / \mathrm{ESL}_{\mathrm{eqMAx}}=9 \mathrm{nH}\end{array}$ & $\begin{array}{l}\text { a) } 10 \mathrm{~A} / 100 \mathrm{~V} / \\
\mathrm{RgExt} . \\
10 \Omega / \delta \mathrm{V}_{\mathrm{Cdec}}=2 \mathrm{~V} \\
\boldsymbol{L}_{\text {beq }} \boldsymbol{M I N}= \\
\boldsymbol{1 4 . 4 n \boldsymbol { H }}\end{array}$ & $\begin{array}{l}\text { b) } 10 \mathrm{~A} / 100 \mathrm{~V} / \\
\mathrm{RgExt} .10 \Omega / 1.7 \mathrm{M} \\
\mathrm{Hz} \\
\boldsymbol{L}_{\boldsymbol{b e q}} \boldsymbol{M A X}= \\
24.3 \boldsymbol{n H}\end{array}$ & $\begin{array}{c}4.5 \mathrm{nH} \\
\text { @10MHz} \\
(3 \text { in } 1 x \text { series })\end{array}$ & \multicolumn{2}{|c|}{$\begin{array}{c}\varnothing \\
\text { (no resonance, only dynamic forward } \\
\text { recovery of the diode) }\end{array}$} \\
\hline $\begin{array}{l}\text { 2.2) } \\
\text { Proposed SiC } \\
\text { (Buck-Type) } \\
\text { 1x Mosfet SiC } \\
\text { CPM2-1200-0025B + } \\
\text { 2x SBD SiC // } \\
\text { CPW4-1200-S015B } \\
\text { (data sheet) } \\
\mathrm{C}_{\text {oss }} @ 100 \mathrm{~V}=470 \mathrm{pF} \\
\mathrm{C}_{\text {oss }} @ 150 \mathrm{~V}=400 \mathrm{pF} \\
\mathrm{C}_{\text {Tdiode }} @ 100 \mathrm{~V}= \\
2 \mathrm{x} 170 \mathrm{pF} \\
\mathrm{C}_{\text {Tdiode }} @ 150 \mathrm{~V}= \\
2 \mathrm{x} 140 \mathrm{pF} \\
\rightarrow \mathrm{K}_{100}=0.58 \\
\rightarrow \mathrm{K}_{150}=0.59 \\
\end{array}$ & $\begin{array}{l}L_{\text {beq MEASURE }}= \\
19.08 \mathrm{nH} @ 10 \mathrm{MHz}\end{array}$ & $\begin{array}{l}\text { a) } 24.5 \mathrm{~A} / 100 \mathrm{~V} / \\
\mathrm{RgExt} \text {. } \\
10 \Omega / \delta \mathrm{V}_{\mathrm{Cdec}}=5 \mathrm{~V}\end{array}$ & $\begin{array}{l}\text { b) } 11.7 \mathrm{~A} / 100 \mathrm{~V} / \\
\text { RgExt. } \\
10 \Omega / 1.6 \mathrm{MHz}\end{array}$ & $\begin{array}{c}5.3 \mathrm{nH} \\
@ 10 M H z \\
(2 \mathrm{~W} \text { in 1x series) }\end{array}$ & $\begin{array}{l}\text { a) } 26 \mathrm{~A} / 150 \mathrm{~V} / \\
\operatorname{RgExt} .0 \Omega / \delta \mathrm{V}_{\mathrm{Coss}} \cong \\
24.5 \mathrm{~V}-\mathrm{b}) 26 \mathrm{~A} / 150 \mathrm{~V} / \\
\operatorname{RgExt} .0 \Omega / 24 \mathrm{kV} \cdot \mathrm{ss}^{-1} \\
\boldsymbol{L}_{\text {sceq } M I N}= \\
1.02 \boldsymbol{n H}- \\
1.63 n \boldsymbol{H}\end{array}$ & $\begin{array}{l}L_{\text {sceq } M A X}= \\
4.2 n H\end{array}$ \\
\hline
\end{tabular}




\section{Conclusion}

The aim of this work was to present a novel approach for integration of multi-phase converters, that combines both monolithic integration and hybrid assembly of Si-chip. This converter integration approach makes use of three multi-pole power chips to realize any generic multi-phase power converter. The operating modes of each power chip were validated independently and in a complete $\mathrm{H}$-bridge inverter, using mixed mode Sentaurus ${ }^{\mathrm{TM}}$ simulations. In order to characterize the commutation loop of the 3-chip approach, two power modules with different technologies ( $\mathrm{Si}$ and $\mathrm{SiC}$ dies) have been realized on PCB substrates and the stray inductances were measured using a precision impedance analyzer. Double-pulse characterizations were also performed to illustrate the effect of stray inductance reduction at the turn-off. For comparison purposes, two classical power converters have been also realized and analyzed. According the results, the proposed layout allows reducing the stray inductance by at least a ratio of two as compared to the classical layout. To further improve the performances, a Direct Lead Bonding (DLB) version for the proposed packaging is envisaged.

\section{References}

[1] Shengnan Li; Tolbert, L.M.; Wang, F.; Fang Zheng Peng, "Reduction of stray inductance in power electronic modules using basic switching cells," Energy Conversion Congress and Exposition (ECCE), 2010 IEEE , vol., no., pp.2686-2691, 12-16 Sept. 2010.

[2] Shengnan Li; Tolbert, L.M.; Fei Wang; Fang Zheng Peng, "Stray Inductance Reduction of Commutation Loop in the P-cell and N-cell-Based IGBT Phase Leg Module", Power Electronics, IEEE Transactions on , vol.29, no.7, pp.3616-3624, July 2014.

[3] Chen, Zheng; Yao, Yiying; Boroyevich, Dushan; Ngo, Khai; Zhang, Wenli, "An ultra-fast SiC phase-leg module in modified hybrid packaging structure," Energy Conversion Congress and Exposition (ECCE), 2014 IEEE , vol., no., pp.2880-2886, 14-18 Sept. 2014.

[4] Reusch, D.; Strydom, J., "Understanding the effect of PCB layout on circuit performance in a high frequency gallium nitride based point of load converter," Applied Power Electronics Conference and Exposition, 2013 IEEE , vol., no., pp.649-655, 17-21 March 2013.

[5] A. El Khadiry, A. Bourennane, M. Breil and F. Richardeau "Monolithically integrated switching cells suitable for high density power conversion" (ISPS'12), Prague, pp. 222-227.

[6] D. Reusch, J. Strydom, A. Lidow, "Monolithic integration of GaN Transistors for Higher Efficiency and Power Density in DC-DC Converters", PCIM Europe 2015, Nuremberg, Germany.

[7] Hara, K.; Wada, S.; Sakano, J.; Oda, T.; Sakurai, K.; Yamashita, H.; Utsumi, T., "600V single chip inverter IC with new SOI technology," Power Semiconductor Devices \& IC's (ISPSD), 2014 IEEE 26th International Symposium on, vol., no., pp.418,421, 15-19 June 2014

[8] D.W Green, E.M Shankar Narayanan, "Fully Isolated High Side and Low Side LIGBTs in Junction Isolation Technology", Power Semiconductor Devices and IC's, ISPSD 2006. IEEE International Symposium on, pp.1-4, 2006.

[9] K. Takahashi et al., "1200V Class Reverse Conducting IGBT optimized for Hard Switching Inverter", PCIM Europe 2014, Nuremberg, Germany.

[10] A. Lale, A. Bourennane, A. El khadiry, F. Richardeau, "A generic Reverse Conducting IGBT structure for monolithic switching cells integration," Power Electronics and Applications (EPE'14-ECCE Europe), 2014 16th European Conference on , vol., no., pp.1,10, 26-28 Aug. 2014.

[11] Bourennane, A.; Tahir, H.; Sanchez, J.-L.; Pont, L.; Sarrabayrouse, G.; Imbernon, E., "High temperature wafer bonding technique for the realization of a voltage and current bidirectional IGBT," Power Semiconductor Devices and ICs (ISPSD), 2011 IEEE 23rd International Symposium on , vol., no., pp.140-143, 23-26 May 2011.

[12] F. Baccar, F. Le Henaff, L. Theolier, S. Azzopardi, E. Woirgard, "Electrical characteristics evolution of the Deep Trench Termination diode based on a finite elements simulation approach", Thermal, mechanical and multi-physics simulation and experiments in microelectronics and microsystems (eurosime), 2014 15th international conference on , vol., no., pp.1-7, 7-9 April 2014.

[13] K. Seto, R. Kamibaba, M. Tsukuda, L. Omura, "Universal trench edge termination design", Power Semiconductor Devices and ICs (ISPSD), 2012 24th International Symposium on , vol., no., pp.161-164, 3-7 June 2012

[14] R. Kamibaba, K. Takahama, I. Omura, "Design of trench termination for high voltage devices" Power Semiconductor Devices \& IC's (ISPSD), 2010 22nd International Symposium on , vol., no., pp.107-110, 6-10 June 2010

[15] Aurélie Lecestre et al., "Anisotropic Deep Reactive Ion Etching without Aspect Ratio Dependence Etching for silicon power devices", PESM 2014 (Plasma Etch and Strip in Microtechnology), May 2014, Grenoble, France.

[16] T. Rossignol, F. Senghor, D. Risaletto, J.-M. Blaquière, F. Richardeau, M. Cousineau, "Switching optimization of WBG power devices on inverter leg "dv/dt - switching energy" trade off and comparison using directly the gate resistance or an additional feedback gate-drain capacitor", PCIM Europe 2013, Nuremberg, 16 18 may 2013.

[17] N. Videau, Ph.D., University of Toulouse, Lab. LAPLACE, 5 May 2014, https://tel.archives-ouvertes.fr/tel00988205/document 